\title{
Incidence and Prevalence of Morbidity and Mortality From Sensitive Conditions to Primary Health Care in Adult Men: A Systematic Review and Meta-analysis Protocol
}

Cácia Régia de Paula ( $\nabla$ caciaregia@gmail.com )

Universidade Federal de Goias https://orcid.org/0000-0001-9781-2918

Cristiane José Borges

Universidade Federal de Jataí Faculdade de Enfermagem

Flavio Henrique Alves de Lima

Universidade Federal de Goias Faculdade de Medicina

Celmo Celeno Porto

Universidade Federal de Goias Faculdade de Medicina

Marcos André Matos

Universidade Federal de Goias Faculdade de Enfermagem

Ana Luiza Lima Sousa

Universidade Federal de Goias Faculdade de Enfermagem

Maria Alves Barbosa

Universidade Federal de Goias Faculdade de Enfermagem

\section{Protocol}

Keywords: Men's health, Hospitalization, Mortality, Morbidity, Sensitive Conditions, Primary Health Care, Healthcare Policy

Posted Date: May 19th, 2020

DOl: https://doi.org/10.21203/rs.3.rs-27659/v1

License: (c) (1) This work is licensed under a Creative Commons Attribution 4.0 International License. Read Full License 


\section{Abstract}

Background: Scientific studies on human health are not remote and show that mortality in this population is increasing. Although male morbidity and mortality rates have a considerable weight in national and international epidemiological profiles, the presence of men in primary health care services is lower than that of women. Many injuries could be avoided if men regularly carried out the first preventive measures. Sensitive Conditions to Primary Care are consolidated as an important marker of access to health services and the resolution capacity of Primary Care. In this systematic review, the objective is to identify what is known about the prevalence and / or incidence of Sensitive Conditions to Primary Care in adult men.

Methods: We will identify the studies through systematic research in PUBMED-MEDLINE, SCOPUS, Web of Science, Embase, Cochrane, BDTD and OpenGrey. The quality assessment of retrieved articles will be carried out using the critical assessment tools of the Joanna Briggs Institute (JBI). The quantitative synthesis of the data will be carried out if the studies are homogeneous and provide adequate result data for meta-analysis. Otherwise, the data will be synthesized, using the narrative synthesis approach.

Discussion: This review will explore theprevalenceand / orincidenceofSensitiveConditionstoprimarycare (prevalenceofhospitalizations; incidenceofhospitalizationsand deaths from ACSC) in adultmenandwillact as a usefulsource for researchers, policymakersand stakeholders whendevelopingandimplementinginterventions for thatgroup.

Systematic review registration: This systematic review protocol was submitted to International Prospective Register of Systematic Reviews (PROSPERO). Submission number: ID 169447. This protocol was prepared using the Preferred Reporting Items for Systematic Reviews and Meta-Analyses for Protocols checklist (PRISMA-P).

\section{Background}

Scientific studies on men's health are not remote. It began in the 1970s, when the importance of gender issues in this area was considered. This path of research revealed a significant paradox: men, who most often display greater social power in relation to women, are underestimated by public policies, with serious consequences for all complexity levels of injuries [1-3].

Studies show that mortality in the male population is increasing and when confronted with the mortality rate of both sexes, it appears that men have the highest rates among the main causes of death. In Brazil the pattern of male mortality rates is about $50 \%$ higher and, considering ages, the highest sex ratio occurs in the age group of 20 to 39 years old, in the proportion of 03 male deaths for each female. In this sense, several studies corroborate the concept that men suffer considerably more from chronic and severe health conditions, when compared to the female population [4-7]. 
In 2009, the mortality rate per 100,000 inhabitants in the age group of 20 to 59 years old for males was 447 against 198 for females in Brazil. In 2014, this rate increased to 464 for men against 206 for women. This discrepancy in mortality indicators between the sexes shows an unfavorable health situation for men that needs to be considered and faced by health services. [8]

Data from the National Household Sample Survey carried out in 2003 and 2008 by the Brazilian Institute of Geography and Statistics (IBGE) regarding the main reason for seeking health care (illness or dental problem) reveal that among men aged 20 to 64 years, the percentage in relation to the total demand per year was $12.1 \%$ (2003) and $14.01 \%$ (2008), while for women in the same age group the percentage was $21.5 \%$ and $23.7 \%$ in those respective years [9-10].

The literature explains that although male morbidity and mortality rates have a considerable weight in national and international epidemiological profiles, it is observed that the presence of men in primary health care services is significantly lower than that of women $[1,11,12,13]$.

Many injuries could be avoided if men regularly carried out primary preventive measures and also if health professionals and scientific professionals were aware of this problem. It is therefore necessary to strengthen and qualify primary care, to promote health and disease prevention [14].

Sensitive Conditions to Primary Care (SCPC) are health conditions that are attended at the primary level of care and, with effective management, reduce the need for hospitalization for such conditions. In this sense, the Ambulatory Care Sensitive Conditions (ACSCs) assess the result of actions and policies developed in the face of health problems $[15,16]$.

In in the 80's, the term Ambulatory Care Sensitive Conditions (ACSCs) was used for the first time in the United States of America [17]. In order to contribute, evaluate and compare the performance of Primary Health Care (PHC) in 2008, the Brazilian list of Sensitive Conditions to Primary Care (SCPC) was created and, to improve the planning and management of health services, the use of hospitalizations for these conditions was established as indicators for the evaluation of PHC services [18].

The SCPCs are consolidated as a significant indicator of access to health services and the resolution capacity of this level of care. The use of this indicator has grown as the coherence of studies that expose the opposite relationship between hospitalizations and access to outpatient services is proven $[15,19]$.

For Boing et al. [20], the expansion of the coverage under the Family Health Strategy (FHS), being associated with the qualification of management and compliance with the conceptual guidelines for PHC, should be considered a priority by those in the health sector. This is confirmed in a study that investigated preventable hospitalizations and coverage of primary health care in Brazil between the years 1998 and 2006, exposing a correlation between the expansion of PHC coverage and reduction in hospitalizations for SCPC in Brazil [21].

Given this, there is no doubt that a health system with a strong orientation to PHC can reduce costs, improve the profile of morbidity and mortality, expand access, and reduce unnecessary hospitalizations, 
and that surveillance programs should include standardized and recognized indicators that can provide support for administration $[22,23]$.

In this context, in one hand we have found systematic review studies addressing hospitalizations for SCPC [24-28]. These reviews point to the importance of strengthening Primary Health Care as a way of preventing hospitalizations and deaths from SCPC, or in the general population or in specific populations such as children. On the other hand, as far as we know, no review has investigated such indicators in the adult male population. This review proposes to focus on hospitalizations and deaths related to SCPC occurring specifically in adult men.

\section{Objectives}

The objectives of this systematic review are:

(1) to identify the prevalence and / or incidence of hospitalizations for Sensitive Conditions to Primary Health Care in adult men;

(2) to identify the incidence of deaths due to Sensitive Conditions to Primary Health Care in adult men;

(3) to assess the tendency of Sensitive Conditions to Primary Health Care in adult men.

\section{Method}

This systematic review protocol was submitted to International Prospective Register of Systematic Reviews (PROSPERO). Submission number: ID 169447. This protocol was prepared using the Preferred Reporting Items for Systematic Reviews and Meta-Analyses for Protocols checklist (PRISMA-P).

\section{Eligibility Criteria}

Studies will be included in the review if they meet the following criteria:

\section{Participants}

The study participants will be adult men aged 20 to 65 years who were hospitalized and / or died due to SCPC. This age group will be used, reflecting the World Health Organization (WHO) definition of aged individuals being 60 years or older in underdeveloped countries and 65 years or older for individuals in developed countries [29].

Studies and scientific papers published in the form of original articles with Brazilian populations, and other countries that included, in their analysis, adult men who were hospitalized or died as a result of SCPC, will be included. Studies and scientific documents published in the form of original articles, with 
specific populations such as the elderly, children, adolescents, and women in any age group will only be included if the results are reported separately for adult men.

\section{Exposure}

The participants must be exposed to Sensitive Conditions to Primary Health care (SCPC). The list of conditions considered sensitive to primary health care will be based on the official Brazilian list of hospitalizations for Sensitive Conditions to Primary Health Care (SCPC), from the Ministry of Health published through Ordinance no. 221 of April 17, 2008, and on the Australian international list of potentially avoidable hospitalizations selected in $2018[18,30]$.

\section{Comparator}

With or without comparison groups.

\section{Outcome}

The main outcomes to be considered are hospitalizations and deaths due to Sensitive Conditions to Primary Care (SCPC) in adult men described in the studies. It is not enough to just refer to the term primary care-sensitive conditions. Additional outcomes will not be considered in this review.

\section{Study Design}

Prevalence and Incidence studies will be included. The studies must report data on the number or frequency (prevalence of hospitalization, incidence of hospitalization, and incidence of deaths) of SCPC.

\section{Language And Publication Status}

There will be no geographical limitation in the included studies. Studies and scientific documents published in Portuguese, English and Spanish will be included. We will include studies published and grey literature from January 1980 [17], the year in which the term Sensitive Conditions was used for the first time in the United States of America, until the final date of collection in the databases.

\section{Exclusion Criteria}

Reports and case series, reviews, qualitative studies, editorials, comments, letters to the editors and responses from the authors will be excluded. Epidemiological studies that do not characterize prevalence and / or incidence studies will be excluded. Several publications of a study will be counted as one study 
only (for example, method documents, secondary analyses, dissertations, republished versions of the same article). Publications from the same study will be checked for additional information (eg, secondary results, follow-up assessments) that was not reported in the main study report.

\section{Search Strategy}

The databases PUBMED-MEDLINE, SCOPUS, Web of Science, Embase, Cochrane, BDTD and OpenGrey will be used.

Literature search strategies will be performed using the Medical Subject Headings (MeSH), Health Sciences Descriptors (Descritores em Ciências da Saúde -DeCS), Embase Thesaurus (Emtree) and words in text. The following keywords or search terms will be utilized in English: sensitive conditions, ambulatory care sensitive, effective access to health services, barriers to access of health services, primary health care, public health policies, healthcare policy, health policy and health services. The Boolean operators "AND" will combine the categories and "OR" will combine the terms in each respective category.

This final search strategy will be reused for the PubMed database and will be adapted for the abovementioned further databases. A draft PubMed search strategy is included in the Appendix (A1).

To ensure saturation of literature, the reference lists of studies included for this review will be used, and also lists of references of relevant reviews identified by this review.

The research team will make attempts to find full texts of the abstracts and results of the studies before exclusion. Contact with the study authors (maximum three times by email) will be done.

\section{Selection Of Studies}

Two reviewers will conduct an independent screening and select titles and abstracts as to their potential relevance. If there is any uncertainty at this stage, the article will remain included. Articles identified using reference lists of included studies will be considered for inclusion based on their title.

For the phase 1 relevance test, the title of the articles identified by the surveys will be sorted according to the following criteria:

1) Is the study related to Sensitive Conditions to Primary Care? (Yes, unclear, or no);

2) It is an epidemiological study of either observational or interventional type? (Yes, unclear, or no);

3) Is the study in Portuguese, English or Spanish? (Yes, unclear, or no). 
For the phase 2 relevance test, the abstracts of the studies selected in phase 1 will be read and selected based on the following criteria:

1) It is a study on hospitalizations and / or deaths due to SCPC in general or specific populations (children, adolescents, the elderly, and women) that refers to hospitalizations or deaths due to SCPC in the male population? (Yes, unclear, or no);

After applying the phase 1 and 2 relevance tests, the reviewers will check for inclusions and exclusions and, in case of disagreement, a third reviewer will be involved as an adjudicator. The statistical test (Kappa) will be applied to quantify the agreement between the reviewers.

The complete text of studies will be read that meet all of the inclusion criteria above and a table with the following information will be produced:

1 Publication details: title, author(s), year, country in which the study was carried out and keywords.

2 Details of study participants: characteristics of the population, including age.

3 Design: type of study, study objectives, data collection method, eligibility (inclusion and exclusion criteria), results and method of analysis of results, prevalence, and incidence of SCPC.

Regarding the selected studies, the following aspects will also be considered: source of funding, existence or not of conflicts of interest and study limitations.

Reviewers will examine the full text of reports and decide if the inclusion criteria are definitely presented. In case additional information is needed, the reviewers will try to contact the authors of the included studies (with a maximum of three attempts by email). Disagreements between reviewers about the eligibility of specific studies through a collective discussion will be resolved by a third reviewer. None of the review authors will be blinded to the titles of the journals or authors or institutions of study. A detailed flowchart will be produced, including methods, such as: identification, sorting, eligibility, and inclusion of items with quantities and an explanatory statement on the basis of the exclusion, and availability through e-mail.

\section{Data Extraction And Management}

The data will be extracted and the articles will be sorted and analyzed. This research process requires the use of specific software for this step. For this, an online data abstraction program (EndNote reference manager) will be used. If repeated studies (duplicates) are identified, they will be removed from the search. The data will be abstracted using specific forms (relevance test 1 and 2; and the table of information with items 1,2 and 3). To avoid double counting, we will include the most embracing report of the particular study only. 


\section{Quality Assessment}

To assess the risk of bias in included studies, the critical assessment tools of the Joanna Briggs Institute (JBI) (http://joannabriggs.org/research/critical-appraisal-tools.html) will be used. A judgement of the possible risk of bias in each of the domains presented in the checklists will be made from the information extracted, classified as "yes", "no", "unclear" or "not applicable". If there are insufficient details reported in the study, the risk of bias will be judged. Graphical representations of possible bias will be computed within and through studies using JBI SUMARI (https://www.jbisumari.org/). The entire process will be carried out independently by two reviewers. The Recommendations Assessment, Development and Evaluation (GRADE) approach will be used to describe the quality of relevant evidence, if applicable.

\section{Summary Of Evidence}

A systematic narrative synthesis will be provided with the information presented in the text and in the tables to summarize and explain the characteristics and results of the included studies. The narrative synthesis will explore the relationship and results within and among the included studies and provide a summary of the prevalence and / or incidence of sensitive conditions in adult men. Finally, a "summary of findings" table will be prepared, as described in the Joanna Briggs Institute's Reviewer manual [31].

After reading the articles, if there is heterogeneity, the meta-analysis will not be performed. In case of homogeneity, the meta-analysis will be carried out. OpenMeta [Analyst] 18 software will be used to perform meta-analysis, after article eligibility and identification of the outcome variables (prevalence of hospitalizations, incidence of hospitalizations and deaths from ACSCs in adult men). The heterogeneity among studies will be assessed by $\mathrm{l}^{2}$ statistics, applying random or random proportion statistics (univariate) depending on heterogeneity, with a $95 \%$ confidence interval $(95 \% \mathrm{Cl})$ for pooled estimates of all three outcomes of this systematic review. Outcomes will be analyzed using raw mean differences. The results will be presented on a forest plot.

Meta-analyses will be conducted by using random-effects method (DerSimonian and Laird), because confidence intervals for the average intervention effect will be wider and corresponding claims of statistical significance will be more conservative [32-34]. Three different tools will be used to assess meta-biases such as publication bias and outcome reporting bias. If 10 or more studies are available, the potential for publication bias will be explored through funnel plots. Additionally, Begg and Mazumdar's test [35] and Egger's test [36] will be used to assess small study effects. Also, according to the tests, if $p<$ 0.05 , publication bias will be detected. If $p \geq 0.05$, there will be no publication bias.

The limitations of the studies will be discussed in detail. Implications of the review, as well as suggestions for future research, will also be provided.

\section{Protocol Changes}


Any substantial changes to this protocol will be recorded in PROSPERO as they occur and will be documented in the final publication.

\section{Dissemination}

The results of the review will be published in a peer-reviewed journal and the results will be supported in accordance with the PRISMA statement (Preferred Reporting Items for Systematic Reviews and MetaAnalyses).

The results will also be released to researchers and policymakers through presentations at academic and non-academic meetings and through social media. If the findings are of interest to the general public, they will be disseminated.

\section{Discussion}

This review will focus on hospitalizations and deaths from SCPC, specifically occurring among adult men. As far as we know, this type of review has not been conducted. This review is expected to be useful to promote discussion on the morbidity and mortality profile of the male population and to awaken a critical eye among administrators and health professionals, so that preventive measures concerning men's health are employed, being a way to progressively decrease the rates of hospitalizations and deaths in this population.

A limitation that may occur is not including studies in languages other than English, Portuguese and Spanish. At the time of data analysis, we may have problems with the lack of homogeneity of the studies. This has been a difficulty for reviewers when undertaking systematic reviews of the literature.

\section{Appendix: A1. Search strategy}

Example search strategy for PubMed: (https://www.ncbi.nlm.nih.gov/pubmed/):

(((("sensitive conditions"[Title/Abstract]) OR "ambulatory care sensitive"[Title/Abstract]) OR "effective access to health services"[Title/Abstract]) OR "barriers to access of health services"[Title/Abstract])) AND (((("primary health care"[Title/Abstract]) OR "public health policies"[Title/Abstract]) OR "healthcare policy" [Title/Abstract]) OR "health policy"[Title/Abstract]) OR "health services"[Title/Abstract])

\section{Abbreviations}

ACSCs: Ambulatory Care Sensitive Conditions; DeCS:Descritores em Ciências da Saúde; Emtree:Embase Thesaurus; FHS:Family Health Strategy; GRADE:Grading of Recommendations Assessment, Development and Evaluation; IBGE:Instituto Brasileiro de Geografia e Estatística; JBI:Joanna Briggs Institute; Medline:Medical Literature Analysis and Retrieval System Online; MeSH:Medical Subject Headings; PHC:Primary Health Care; PRISMA:Preferred Reporting Items for Systematic Reviews and Meta-Analyses; 
PRISMA-P:Preferred Reporting Items for Systematic Reviews and Meta-Analyses Protocols; SCPC:Sensitive Conditions to Primary Health Care; WHO:World Health Organization.

\section{Declarations}

\section{Funding}

This systematic review will be financed with its reviewers' own resources. Non-financial sources include the provision of a library and database by the Federal University of Goiás in Goiânia, Goiás.

\section{Author's contributions}

CRP, FHAL and CJB authored the protocol, the search strategy, the manuscript and the record of the systematic review. ALLS and MAM contributed to the design of the questions and research protocol, critically reviewed and provided comments on the manuscript drafts, and agreed to the final version submitted. CCP and MAB critically reviewed and provided comments on the draft manuscript and agreed with the final version submitted. All authors read, gave feedback and approved the final manuscript.

\section{Ethical approval and consent to participate:}

Not applicable.

\section{Consent for publication:}

Not applicable.

\section{Competitive interests:}

The authors declare that they have no competing interests.

\section{References}

1. Courtenay WH. Constructions of masculinity and their influence on men's well-being: a theory of gender and health. Soc Sci Med [Internet].2000; 50 (1): 385-401. https://www.ncbi.nlm.nih.gov/pubmed/10741575. Accessed 21 Jun 2019.

2. Gomes R. A Saúde do Homem em Debate. Apresentação. Rio de Janeiro: Fiocruz; 2011. pp. 11-8.

3. Coelho, et al. Política Nacional de Atenção Integral a Saúde do Homem. Florianópolis: Universidade Federal de Santa Catarina; 2018. 66 p. 
4. https://www.portalarquivos2.saude.gov.br > pdf > novembro > livroPol-ticas-2018. Accessed 25 Jun 2019.

5. Courtenay WH, Keeling RP. Men, Gender, and Health: Toward an Interdisciplinary Approach. J Am Coll Health 2000; 48(6):243-246. https://www.ncbi.nlm.nih.gov/pubmed/10863867. Accessed 27 Jun 2019.

6. Laurenti R, Mello-Jorge MHP, Gotlieb SLD. Perfil epidemiológico da morbi-mortalidade masculina. Ciência \& Saúde Coletiva [Internet]. 2005; 10: 35-46. https://www.scielosp.org/article/csc/2005.v10n1/35-46/pt/. Accessed 25 Jun 2019.

7. Figueiredo Wagner. Assistência à saúde dos homens: um desafio para os serviços de atenção primária. Ciênc. saúde coletiva [Internet]. 2005 Mar; 10(1): 105-109. http://www.scielo.br/scielo.php?script=sci_arttext\&pid=S1413-81232005000100017\&lng=en. https://doi.org/10.1590/S1413-81232005000100017. Accessed 21 Jun 2019.

8. Gomes R, Nascimento EF do, Araújo FC de. Por que os homens buscam menos os serviços de saúde do que as mulheres? As explicações de homens com baixa escolaridade e homens com ensino superior. Cadernos de Saúde Pública. 2007; 23: 565 - 74. http://www.scielo.br/scielo.php? pid=S0102-311X2007000300015\&script=sci_abstract\&tlng=pt. Accessed 26 Jun 2019.

9. Brasil. Ministério da Saúde. Perfil da morbimortalidade masculina no Brasil. Brasília: Ministério da Saúde [Internet]. 2018; 52 p. em:

http://portalarquivos2.saude.gov.br/images/pdf/2018/fevereiro/19/Perfil-da-morbimortalidademasculina-no-Brasil.pdf. Accessed 07 Jul 2019.

10. Instituto Brasileiro de Geografia e Estatística Instituto Brasileiro de Geografia e Estatística. Pesquisa Nacional por Amostra de Domicílios 2003 [Internet]. Rio de Janeiro IBGE, 2003; https://biblioteca.ibge.gov.br/visualizacao/livros/liv6194.pdf. Accessed 01 Jul 2019.

11. Instituto Brasileiro de Geografia e Estatística. Pesquisa Nacional por Amostra de Domicílios 2008 [Internet]. Rio de Janeiro IBGE, 2008; https://sidra.ibge.gov.br/tabela/2508. Accessed 01 Jul 2019.

12. Pinheiro, et al. Gênero, morbidade, acesso e utilização de serviços de saúde no Brasil. Ciênc Saúde Coletiva [Internet]. 2002; 7(4): 687-707. http://www.scielo.br/pdf/csc/v7n4/14599.pdf.Accessed 21 Jun 2019.

13. Gomes R, et al. Os homens não vêm! Ausência e/ou invisibilidade masculina na atenção primária. Ciência \& saúde coletiva [Internet] 2011; 16: 983-992. http://www.scielo.br/scielo.php? script=sci_arttext\&pid=S1413-81232011000700030. Accessed 15 Out 2019.

14. Moura et al. Atenção à saúde dos homens no âmbito da Estratégia Saúde da Família. Ciência \& Saúde Coletiva. 2014; 19 (2): 429-38. http://www.scielo.br/scielo.php?pid=S141381232014000200429\&script=sci_abstract\&tlng=pt. Accessed 15 Out 2019.

15. Ministério da Saúde. Política Nacional de Atenção Integral à Saúde do Homem. Plano de Ação Nacional (Princípios de Diretrizes). Brasília DF; 2008. 
16. http://www.portalarquivos2.saude.gov.br > pdf > novembro , livroPol-ticas-2018. Accessed 20 Out 2019.

17. Alfradique ME, et al. Ambulatory care sensitive hospitalizations: elaboration of Brazilian list as a tool for measuring health system performance (Project ICSAP - Brazil). Cad Saúde Publica. 2009; 25(6): 1337-49. http://www.scielo.br/scielo.php?pid=S0102-311X2009000600016\&script=sci_abstract. Accessed 20 Out 2019.

18. Nedel FB, et al. Programa Saúde da Família e condições sensíveis à atenção primária, Bagé (RS). Rev. Saúde Pública [Internet]. 2008 Dez; 42(6): 1041-1052. http://www.scielo.br/scielo.php? script=sci_arttext\&pid=S0034-89102008000600010\&lng=en. Accessed 20 Out 2019.

19. Rehem TCMSB, Egry EY. Internações por condições sensíveis à atenção primária no estado de São Paulo. Ciência \& Saúde Coletiva [Internet]. 2011;16: 4755-66. Disponível em:

https://www.scielosp.org/scielo.php?pid=S1413-81232011001300024\&script=sci_arttext\&tlng=en. Accessed 21 Jun 2019.

20. Brasil. Ministério da Saúde. Portaria no. 221/SAS de 17 de abril de 2008, que define a Lista Brasileira de Internações por Condições Sensíveis à Atenção Primária. Diário Oficial da União da República Federativa do Brasil, 2008; 18 abr. https://www.bvsms.saude.gov.br > saudelegis > sas > 2008 > prt0221_17_04_2008. Accessed 21 Jun 2019.

21. Cadernos de Saúde Pública [Internet] $2012000500004 \&$ script=sci_arttext\&tlng=PT. Accessed 14 Out 2019.

Campos AZD, Theme-Filha MM. Internações por condições sensíveis à atenção primária em Campo Grande, Mato Grosso do Sul, Brasil, 2000 a 2009. Cadernos de Saúde Pública [Internet] 2012; 28:845-855. https://www.scielosp.org/scielo.php?pid=S0102311X2012000500004\&script=sci_arttext\&tIng=PT. Accessed 14 Out 2019.

22. Boing et al. Redução das internações por condições sensíveis à atenção primária no Brasil entre 1998-2009. Rev. Saúde Pública [Internet]. 2012; 46(2): 359-366.http://www.scielo.br/scielo.php? script=sci_arttext\&pid=S0034-89102012000200019\&Ing=en. Accessed 28 Jul 2019.

23. Ceccon RF, Meneghel SN, Viecili PRN. Internações por condições sensíveis à atenção primária e ampliação da Saúde da Família no Brasil: um estudo ecológico. Rev. bras. epidemiol. [Internet]. 2014; 17(4): 968-977. http://www.scielo.br/scielo.php?script=sci_arttext\&pid=S1415790X2014000400968\&Ing=en. Accessed 03 Nov 2019.

24. Mendes EV. $O$ cuidado das condições crônicas na atenção primária à saúde: o imperativo da consolidação da estratégia da saúde da família. Brasília: Organização Pan-Americana da Saúde; 2012. https://periodicos.unifor.br/RBPS/article/view/7839. Accessed 27 Jul 2019.

25. Skinner HG, Coffey R, Jones J, Heslin KC, Moy E. The effects of multiple chronic conditions on hospitalization costs and utilization for ambulatory care sensitive conditions in the United States: a nationally representative cross-sectional study. BMC Health Serv Res. 2016; 16(1): 77. https://www.ncbi.nlm.nih.gov/pubmed/26926525. Accessed 02 Set 2019. 
26. Pedraza DF, Araujo EMN de. Internações das crianças brasileiras menores de cinco anos: revisão sistemática da literatura. Epidemiol. Serv. Saúde [Internet].2017mar;26(1):169-182. http://www.scielo.br/scielo.php?script=sci_arttext\&pid=S2237-96222017000100169\&lng=en. Accessed 03 Nov 2019.

27. Nedel FB, Facchini LA, Martín M, Navarro A. Características da atenção básica associadas ao risco de internar por condições sensíveis à atenção primária: revisão sistemática da literatura. Epidemiol Serv Saude. 2010; 19(1): 61-75.

https://pdfs.semanticscholar.org/35f5/f5cb52eb57f59f444a968395f2d73763d549.pdf. Accessed 04 Nov 2019.

28. Albrecht RHM, Dias AB, Melo WA de. Condições Sensíveis a Atenção Primária: revisão sistemática da literatura brasileira In: VIII EPCC - Encontro Internacional de Produção Científica Cesumar, 2013 Maringá/PR, Anais Eletrônico VIII EPCC - Encontro Internacional de Produção Científica Cesumar. http://www.cesumar.br/prppge/pesquisa/epcc2013/oit_mostra/Augusto_Braun_Dias.pdf. Accessed 05 Nov 2019.

29. Gibson OR, Segal L, McDermott RA. A systematic review of evidence on the association between hospitalisation for chronic disease related ambulatory care sensitive conditions and primary health care resourcing. BMC Health Services Research. [Internet] 2013 [acesso em 2019 nov 03] 13:336. https://www.ncbi.nlm.nih.gov/pmc/articles/PMC3765736/pdf/1472-6963-13-336.pdf. Accessed 05 Nov 2019.

30. 10.1186 / s12913-015-0964-3

Busby J, Purdy S, Hollingworth W. A systematic review of the magnitude and cause of geographic variation in unplanned hospital admission rates and length of stay for ambulatory care sensitive conditions. BMC Health Serv Res [Internet] 2015; 15: 324.

https://www.ncbi.nlm.nih.gov/pmc/articles/PMC4535775/. doi: 10.1186 / s12913-015-0964-3. PMID: 26268576; PMCID: PMC4535775. Accessed 03 Nov 2019.

31. 10.1590/S0103-21002005000400011

Mendes MRSSB, Gusmão JL de, Faro ACM e, Leite RCBO. A situação social do idoso no Brasil: uma breve consideração. Acta paul. enferm. [Internet]. 2005 Dez;18(4):422-426. http://www.scielo.br/scielo.php?script=sci_arttext\&pid=S0103-21002005000400011\&lng=en. http://dx.doi.org/10.1590/S0103-21002005000400011. Accessed 25 Nov 2019.

32. Australian Institute of Health and Welfare. National Healthcare Agreement: PI 18-Selected potentially preventable hospitalisations, 2018.

https://meteor.aihw.gov.au/content/index.phtml/itemld/658499. Accessed 25 Jun 2019.

33. Aromataris E, Munn Z (Editores). Manual do Revisor do Instituto Joanna Briggs. The Joanna Briggs Institute, 2017. https://reviewersmanual.joannabriggs.org/. Accessed 26 Set 2019.

34. Higgins JP, Thompson SG. Quantifying heterogeneity in a meta-analysis. Stat Med. 2002;21(11):1539-58. https://www.ncbi.nlm.nih.gov/pubmed/12111919. Accessed 25 Nov 2019. 
35. Higgins JP, Thompson SG, Deeks JJ, Altman DG. Measuring inconsistency in meta-analyses. BMJ. 2003;327(7414):557-60. https://www.ncbi.nlm.nih.gov/pubmed/12958120. Accessed 24 Nov 219.

36. Borenstein M, Hedges LV, Higgins JPT, Rothstein HR. Introduction to metaanalysis. West Sussex, UK: Wiley; 2009. https://www.wiley.com/en-us/Introduction+to+Meta+Analysis-p-9780470057247. Accessed 25 Nov 2019.

37. $2307 / 2533446$

Begg CB, Mazumdar M. Operating characteristics of a rank correlation test for publication bias. Biometrics. 1994;50(4):1088-101. https://doi.org/10. 2307/2533446.

38. Egger M, Smith GD, Schneider M, Minder C. Bias in meta-analysis detected by a simple, graphical test. Br Med J. 1997;315(7109):629-34. https://doi.org/10.1136/bmj.315.7109.629. dx.doi.org.

\section{Supplementary Files}

This is a list of supplementary files associated with this preprint. Click to download.

- Letterofpresentation ofarticleforsubmission.pdf

- PRISMAP2015IncidenceandPrevalenceofMorbidity.pdf 